\title{
Pengembangan Modul Dukungan Suami untuk Mencapai Keseimbangan Kerja-Keluarga
}

\author{
Arri Handayani ${ }^{1}$, Primaningrum Dian $\mathbf{M}^{2}$ \\ 1,2Program Studi Bimbingan dan Konseling Fakultas Ilmu Pendidikan, Universitas PGRI \\ Semarang \\ Jl. Sidodadi Timur No.24, Karangtempel, Kec. Semarang Tim., Kota Semarang, Jawa Tengah \\ e-mail : arrihandayani@upgris.ac.id ${ }^{1}$, primaningrum.dian@gmail.com ${ }^{2}$
}

Article History:

Received

22 April 2021

Review

19 Mei 2021

Revised

9 Juni 2021

Accepted

10 Juni 2021

Published

23 Juni 2021

Reviewer A:

Fendy Suhariadi
Abstract. This study is a development using Borg and Gall model. It aims to compile module on husband support to achieve work-family balance for working mothers. The researcher involved 15 respondents for initial data collection, 30 respondents for the small group trial, and 4 judgment experts (family psychology, industrial psychology, Himpaudi research and development, and media). For the big group, there were 50 respondents involved. Data were collected using open and closed questioners and self-assessment scale. Data collected, both qualitative and quantitative, were then analyzed descriptively. Research results show that 1). The result of module validation shows that the layout and concept of the module is categorized as good with slight revision. However, this module is suitable for the training on husband support to achieve work-family balance. 2). The implementation of the module in both small and big group shows that thea participants have shown improvement in their understanding and perception of husband support. This shows that husband support module compiled effectively can increase participants' skill and understanding in achieving work-family balance.

keywords : husband support module, work-family balance, working mother

Abstrak. Penelitian ini merupakan penelitian pengembangan dengan model Borg dan Gall yang bertujuan menyusun modul dukungan suami untuk mencapai keseimbangan kerja-keluarga pada ibu bekerja. Peneliti melibatkan 15 responden untuk pengambilan data awal, 30 responden pada uji coba kelompok kecil serta 4 orang expert judgement (ahli psikologi keluarga, psikologi industri, litbang Himpaudi, dan ahli media). Untuk kelompok lebih luas peneliti melibatkan 50 responden. Instrumen pengumpulan data berupa angket terbuka dan tertutup serta skala penilaian diri. Hasil penelitian menunjukkan 1). Hasil validasi modul secara tampilan maupun konsep termasuk dalam kategori baik, dengan sedikit perbaikan. Meskipun demikian, modul ini sesuai dalam mendukung pelatihan dukungan suami dalam mencapai keseimbangan kerjakeluarga. 2). Implementasi modul pada kelompok kecil maupun kelompok yang lebih luas menunjukkan bahwa pemahaman serta persepsi dukungan suami yang dirasakan peserta mengalami peningkatan. Hal ini menunjukkan bahwa modul dukungan suami secara efektif mampu meningkatkan pemahaman dan keterampilan peserta dalam mencapai keseimbangan kerja-keluarga.

Kata kunci : modul dukungan suami, keseimbangan kerja-keluarga, ibu bekerja 


\section{Pendahuluan}

Sejalan dengan kesejajaran laki-laki dan perempuan, semakin banyak ibu bekerja di ranah publik. Keterlibatan ibu dalam dunia kerja pada dasarnya dapat memberikan dampak positif maupun negatif. Dampak positif diantaranya adalah ibu bekerja memperoleh ketrampilan, adanya emosi positif, harga diri dan kepuasan hidup (Ruderman, Ohlott, Panser \& King 2002). Sementara itu, dampak negatif yang mungkin terjadi diantaranya terdapat persoalan kehidupan dalam pekerjaan serta keluarga, seperti konflik antara peran pekerjaan dan keluarga (Handayani, 2008, 2012), depresi (Aycan \& Eskin, 2005; Major, Klein, \& Ehrhart, 2002), stress (Judge \& Colquitt, 2004; Parasuraman \& Simmers, 2001), kurangnya waktu bersama keluarga, sehingga tidak dapat sepenuhnya mengurus anak. Tidak jarang juga perempuan berperan ganda karena sudah sibuk dengan peran gandanya tidak memiliki waktu untuk diri sendiri (Putri, Respati, \& Safitri, 2009).

Dalam kondisi senyatanya, ibu bekerja lebih mengalami konflik dibanding laki-laki, karena peran perempuan yang berbeda dalam keluarga, terutama pada ibu bekerja yang mempunyai anak berusia muda (Kinnunen \& Mauno, 1998; Martins, Eddleston \& Veiga, 2002). Hal ini karena pekerjaan perempuan dalam keluarga lebih bersifat rutinitas, seperti tanggung jawab terhadap anak terutama untuk anak berusia di bawah 12 tahun, sedangkan pekerjaan laki-laki lebih bersifat fleksibel (Ford, Heinen, \& Langkamer, 2007). Karena tanggung jawab tersebut para ibu masih harus melakukan banyak hal setelah melakukan aktivitas di kantor.

Menurut Handayani, Maulia, \& Yulianti (2012) seorang perempuan yang bekerja, memiliki peran ganda yang harus dijalankan pada saat bersamaan. Menjalankan peran ganda rentan akan konflik. Dari hasil penelitian Handayani tersebut diketahui bahwa kinerja dosen perempuan dipengaruhi oleh konflik kerja keluarga. Sejalan dengan itu, hasil penelitian Handayani (2008) menunjukkan bahwa ada kalanya perempuan juga mengalami konflik sehubungan dengan peran gandanya meskipun mendapat dukungan suami. Hal ini misalnya ketika anak sakit. Pada umumnya ibu bekerja tetap tidak tega meninggalkan anak di rumah dalam kondisi sedang sakit.

Melihat dari situasi tersebut, dapat dipahami bahwa sebagian besar ibu bekerja tetap mengalami konflik dalam mencapai keseimbangan kerja-keluarga, karena ketika berada dalam ranah kerja maupun keluarga, ada satu sisi yang diuntungkan, tetapi di sisi lain ada sesuatu yang harus dikorbankan. Padahal ketika ketika ibu bekerja dapat mencapai keseimbangan kerja-keluarga, akan bermanfaat baik dari sisi organisasi, diri 
sendiri maupun keluarga. Dari sisi organisasi, diantaranya adanya komitmen kerja dan produktivitas kerja (Grzywacz \& Marks, 2000).

Sebagai seorang karyawan juga merasa diuntungkan dengan adanya keseimbangan kerja- keluarga, karena akan berkontribusi pada kesejahteraan individu, kesehatan yang baik, mampu berfungsi dengan baik dalam lingkungan bermasyarakat (Halpern, 2005), adanya kepuasan keluarga, kepuasan perkawinan, performansi keluarga, keberfungsian keluarga (Carlson, Kacmar, Wayne, \& Grzywacz, 2006) dan kesejahteraan keluarga (Greenhause, Collins, \& Shaw, 2003). Hasil penelitian Handayani \& Munawar (2015) diketahui bahwa tumbuh kembang anak anak optimal ketika ibu mampu menyeimbangkan pekerjaan dan keluarga dan merasa puas karena bantuan suami dalam pengasuhan anak. Pada dasarnya keseimbangan kerja-keluarga adalah keadaan ketika seseorang mampu mengatur berbagai tanggungjawab dan menentukan skala prioritas sehingga merasakan adanya keterlibatan dan kepuasan peran yang sama dalam domain kerja dan keluarga, dengan konflik yang minimal, karena (Handayani, Afiatin, Adiyanti, 2015).

Pada awalnya keseimbangan kerja keluarga dianggap oleh para peneliti ketika tidak ditemukan konflik di dalamnya. Dalam tahap selanjutnya, tidak adanya konflik saja tidak cukup untuk menunjukkan adanya keseimbangan kerja-keluarga (Grzywacz \& Carlson, 2007; Valcour, 2007), tetapi perlu adanya pertimbangan dari sisi positif. Konsep work family facilitation, merupakan komponen kedua yang perlu dipertimbangkan dalam mengindikasikan adanya keseimbangan kerja-keluarga (Grzywacz \& Marks, 2000; Voydanoff, 2004). Dengan demikian keseimbangan kerja-keluarga mempertimbangkan aspek positif dan negatif dalam domain pekerjaan keluarga (Carlson, et al, 2006; Grzywacz \& Marks, 2000; Voydanoff, 2004).

Selanjutnya pemahaman dari (Clark, 2000; Greenhause et al., 2003; MacDermind, 1996) diketahui bahwa keseimbangan kerja-keluarga pada intinya adalah adanya keterlibatan dan kepuasan peran yang sama dalam domain kerja dan keluarga dengan konflik yang minimal. Menurut Dewi (2013) keseimbangan peran lebih banyak berkaitan dengan persepsi individual dibandingkan dengan status dan beban kerja itu sendiri. Kondisi ini sejalan dengan hasil penelitian (Handayani, Afiatin, Adiyanti, 2015) bahwa keseimbangan kerja keluarga adalah ketika seseorang merasakan adanya keterlibatan dan kepuasan peran yang sama dalam domain kerja dan keluarga, dengan konflik yang minimal, karena kemampuannya dalam menentukan skala prioritas yang bersifat subjektif. 
Melihat kondisi demikian, betapa penting seorang ibu bekerja berupaya untuk mencapai keseimbangan kerja-keluarga. Berdasarkan penelitian Handayani (2017) tentang model keseimbangan kerja-keluarga diketahui bahwa salah satu faktor yang berkontribusi dalam mencapai keseimbangan kerja-keluarga adalah dukungan suami. Dukungan suami menceminkan persepsi terhadap terpenuhinya kebutuhan, yang membantu individu melindungi dari efek stress baik secara nyata maupun secara emosional, yang pada akhirnya berpengaruh pada tingkah laku penerimanya. Seseorang dapat mengatasi masalahnya berdasarkan persepsi dukungan sosial yang dimiliki ketika ada dukungan dan ada seseorang yang dapat diandalkan pada saat dibutuhkan (Handayani, 2017).

Pada dasarnya variabel dukungan sosial menceminkan persepsi terhadap terpenuhinya kebutuhan yang membantu individu melindungi dari efek stress, baik secara nyata maupun secara emosional yang pada akhirnya akan berpengaruh pada tingkah laku penerimanya. Dengan demikian, dukungan sosial dicirikan oleh tindakan tanggap terhadap kebutuhan orang lain (Wadsworth \& Owens, 2007). Seseorang berdasarkan persepsi dukungan sosial yang dimilikinya merasa memperoleh dukungan dan merasa ada seseorang yang dapat diandalkan pada saat dibutuhkan sehingga akan dapat mengatasi masalahnya.

Menurut Aycan \& Eskin (2005) dukungan suami menunjukkan adanya saran, pemahaman, perhatian serta pertolongan suami. Dukungan suami yang diterima ibu bekerja menunjukkan adanya perhatian secara nyata dari suami. Lebih lanjut Adam, et al. (1996) mengatakan bahwa bantuan yang diberikan suami adalah dukungan suami. Dalam hal ini suami adalah orang pertama dan utama dalam memberi dorongan dan dukungan pada istri, sebelum pihak lain turut memberikannya.

Berdasarkan review literatur (Adam, et al., 1996; Aycan \& Eskin, 2005; Erdwins, et al, 2001; King, et al, 1995; Wayne \& Stevens, 2006) pada dasarnya ada dua bentuk dukungan suami, yaitu dukungan emosi dan dukungan instrumental. Dukungan emosi dilakukan dengan ikhlas untuk kesejahteraan pasangan, meliputi empati, mau mendengarkan, memahami, afirmasi afeksi, ataupun pemberian saran. Sementara itu adanya pertolongan nyata dari suami yang berhubungan dengan tugas-tugas rumah tangga dan pengasuhan anak merupakan dukungan instrumental. (Adam, et al., 1996; Aycan \& Eskin, 2005; Erdwins, et al, 2001; King, 1995; Wayne \& Stevens, 2006). Dalam hal ini termasuk sikap dan tingkah laku yang bertujuan memfasilitasi keluarga dengan berbagi 
tugas rumah tangga dengan mengakomodasikan jadwal kerja pasangan atau kebutuhan kerja (Aycan \& Eskin, 2005).

Menurut Clark (2000) adanya dukungan memainkan peran penting dalam mencapai keseimbangan kerja-keluarga. Sejalan dengan itu, Baran (2012), Lee, et al. (2013) menyebutkan bahwa adanya dukungan personal yang tinggi, terutama dari suami dan anggota keluarga akan lebih berarti daripada dukungan di tempat kerja, khususnya pada perempuan bekerja. Karena suami istri saling berinteraksi dan berbagi satu sama lain tentang pengalaman berbagai peran kehidupan, maka pasangan merupakan unsur dari keluarga yang paling penting (Fischlmayr \& Kollinger, 2010; Jianwei \& Yuxin, 2011).

Menurut Greenhaus, et al. (2011) suami dapat memberikan dukungan emosi terhadap pasangan dengan menawarkan pertolongan ataupun saran dalam rangka mempertemukan tanggung jawab pekerjaan dan keluarga. Sehubungan dengan hal tersebut, hasil penelitian Lee et al. (2013) terungkap bahwa ada hubungan antara dukungan suami dengan peran keseimbangan pada para perempuan bekerja penuh waktu.

Menurut Ehrenberg, et al., (2001) dukungan yang diterima dari pasangan mempunyai pengaruh positif tentang penilaian pasangan tentang ketrampilan parenting. Dengan adanya peran ayah, secara tidak langsung pun berdampak tehadap perkembangan anak. Ketika ayah terlibat dalam pengasuhan anak, berarti ayah turut membantu peran ibu dalam mengurus rumah tangga. Melalui pengasuhan bersama, ibu merasa lebih ringan dan lebih nyaman (Handayani \& Munawar, 2015). Berdasarkan kondisi tersebut dapat disimpulkan bahwa dukungan suami berpengaruh terhadap keseimbangan kerja-keluarga. Para ibu bekerja membutuhkan dukungan suami untuk membantu mempertemukan tuntutan pekerjaan dan keluarga. Hal ini berarti dengan adanya dukungan suami dapat membantu ibu bekerja mencapai keseimbangan kerja-keluarga.

Permasalahan yang muncul, walaupun diketahui bahwa dukungan suami berkontribusi dalam mencapai keseimbangan kerja-keluarga, akan tetapi dukungan suami seperti apa yang mampu mempengaruhi ibu bekerja untuk mencapai keseimbangan kerjakeluarga?

\section{Metode}

Penelitian ini menggunakan metode Research and Development (R\&D) mengacu Gall, et al. (2003) dengan luaran penelitian modul dukungan suami. Prosedur pengembangan modul ada beberapa tahapan yang harus ditempuh antara lain studi pendahuluan, perencanaan, pengembangan model hipotetik, penelaahan model hipotetik, 
revisi, uji coba terbatas, revisi hasil uji coba, uji coba lebih luas, revisi model akhir, dan disemiasi dan sosialisasi (Gall, et al., 2003)

Secara keseluruhan penelitian ini terbagi menjadi dua tahapan dan penelitian ini merupakan penelitian tahap pertama. Kegiatan yang dilakukan meliputi : (1) persiapan pengembangan modul; dengan memperhatikan kajian teori terkait dengan variabel penelitian. Untuk mendapatkan data/ informasi di lapangan, maka peneliti melakukan FGD, (2) data-data hasil FGD selanjutnya kumpulkan untuk digunakan sebagai bahan dalam merancang materi modul, (3) merumuskan desain modul dukungan suami, (4) uji kelayakan modul oleh para expert judgement, 5) Revisi draft modul, berdasarkan masukan para expert judgement, (6) melaksanakan uji coba terbatas dan mendeskripsikan data hasil uji coba. Uji coba terbatas dilaksanakan pada ibu bekerja di Kota Semarang dengan karakteristik populasi mempunyai anak balita, suami bekerja dan tinggal dalam satu rumah, dengan jumlah responden 30 orang. Instrumen untuk mengukur tingkat pemahaman dukungan suami yang dirasakan istri menggunakan penilaian diri.

\section{Hasil}

\section{Data FGD untuk menggali data modul dukungan suami}

FGD dilakukan untuk menampung mendapatkan informasi, pendapat dan gagasan yang dirasakan responden berkaitan dengan dukungan suami yang dirasakan subjek. FGD dihadiri oleh 15 responden, dan tiga diantaranya adalah para suami.

Berdasarkan hasil FGD diketahui bahwa dukungan suami yang dirasakan istri meliputi adanya rasa empati, perhatian yang merupakan dukungan emosional. Seorang istri juga merasakan bahwa suami adalah penolong sejatinya, bahwa ketika ada masalah, suami selalu mampu menjadi penolongnya.

\section{Materi Modul Dukungan Suami}

Modul dukungan suami untuk mencapai keseimbangan kerja-keluarga ini terdiri dari empat sesi, yaitu sesi pengantar, dua sesi materi utama dan satu sesi penutup. Pada materi utama difokuskan pada hasil FGD serta hasil riset Handayani (2017) tentang model keseimbangan kerja-keluarga pada ibu bekerja yang di dalamnya terdapat aspek-aspek dukungan suami. Aspek-aspek tersebut adalah adanya dukungan emosional dan dukungan instrumental.

\section{Hasil Expert judgment}

Expert judgement dalam penelitian ini adalah para ahli di bidang psikologi keluarga, psikologi industry, litbang Himpaudi, dan ahli media. Berikut adalah hasil dari masing-masing expert judgement : 


\section{a. Hasil expert judgement bidang Psikologi Keluarga}

Berdasarkan dari hasil expert judgement di bidang psikologi keluarga diperoleh skor total sebesar 67, dan setelah dianalisis melalui data kategori bergolong termasuk dalam kategori baik. Sedangkan hasil analisis kualitatif dikritisi bahwa dukungan yang diberikan suami ke istri sangat unik, maka perlu dipertimbangkan tentang pemenuhan kebutuhan seksual (dukungan emosi) dan dukungan finansial (dukungan instrumental).

\section{b. Hasil expert judgement bidang Psikologi Industri}

Berdasarkan dari hasil expert judgement di bidang psikologi industri diperoleh skor total sebesar 64, dan setelah dianalisis melalui data kategori bergolong termasuk dalam kategori baik. Sedangkan hasil analisis kualitatif menunjukkan bahwa modul secara konten telah menjabarkan tentang adanya dukungan suami.

Berdasarkan hasil validasi dari expert judment bidang psikologi industri ini diperoleh hasil bahwa modul yang telah disusun dapat digunakan namun harus dilakukan beberapa revisi. Keunggulan modul ini adalah setelah peserta mengikuti pelatihan, peserta akan lebih mengetahui dengan pasti apa yang dimaksud dukungan suami, baik secara nyata yang didapatkan maupun secara emosi yang dirasakan.

\section{c. Hasil expert judgement bidang Litbang}

Selanjutnya untuk expert judgement dari Litbang Himpaudi menunjukkan bahwa modul secara konten telah sesuai dalam mendukung pelatihan dukungan suami untuk mencapai keseimbangan kerja keluarga. Secara detail disampaikan bahwa modul ini mampu memberi pemahaman kepada peserta tentang persepsi pada bentuk dukungan suami (dukungan emosi dan dukungan instrumental). Selanjutnya juga perlu lebih digali pengalaman pribadi dari peserta. Berdasarkan hasil analisis kuantitatif diperoleh skor total 66, dan ini pun dalam data kategori bergolong termasuk dalam kriteria baik.

\section{d. Hasil expert judgement bidang media}

Terakhir adalah expert judgement di bidang media. Beberapa hal yang direview meliputi data teknis buku, desain dan elemen verbal. Hasil review kualitatif dari expert judgement di bidang media menunjukkan bahwa secara data teknis buku, lebih baik posisi modul dalam bentuk portrait, tidak landscape. Hal ini agar lebih efektif dan ergonomis. Selanjutnya berkaitan dengan desain, agar efektif dalam keterbacaannya, perlu penyesuaian bentuk huruf yang kekinian dan tidak melelahkan.

Selanjutnya juga perlu diperhatikan dalam penggunaan warna, agar tidak terlalu banyak dalam penggunaannya yang terkesan mencolok. Lebih baik sesuai dengan warna yang ada dalam gambar cover. Penggunaan header dan footer seminimal mungkin, tidak 
menggunakan gambar yang terlalu besar, karena dapat mengganggu peserta pelatihan dalam membaca modul. Sementara itu hasil secara kuantitatif menunjukkan skor 55, yang dalam kategori bergolong termasuk dalam kategori baik, dan secara umum modul dapat digunakan setelah dilakukan perbaikan.

\section{Hasil Uji keterbacaan}

Sebelum uji coba terbatas dilakukan, diawali dengan uji keterbacaan evaluasi yang dilakukan oleh 10 orang responden untuk mengetahui apakah modul mudah dipahami responden. Hasil uji keterbacaan menyatakan bahwa pada umumnya bahasa yang digunakan dalam modul dapat dipahami oleh responden.

\section{Hasil uji coba terbatas dan hasil uji coba kelompok luas}

Secara umum dari kesan yang disampaikan oleh para peserta pelatihan, bahwa mereka pada awalnya belum sepenuhnya memahami tentang keseimbangan kerjakeluarga ataupun dukungan suami. Setelah mengikuti pelatihan ini peserta akhirnya memahami dan berusaha menerapkan apa yang sudah diperoleh dalam pelatihan ini. Hasil perbedaan sebelum dan sesudah mengikuti pelatihan seperangkat modul keseimbangan kerja-keluarga adalah pada saat uji coba terbatas sebesar 12,31 sebelum pelatihan dan 14, 51 sesudah pelatihan. Sedangkan hasil pada uji coba kelompok lebih luas menunjukkan skor 13,22 sebelum pelatihan dan 14,88 sesudah pelatihan. Hal ini menunjukkan bahwa modul dukungan suami yang telah disusun secara efektif mampu meningkatkan pemahaman dan keterampilan peserta dalam mencapai keseimbangan kerja-keluarga.

\section{Pembahasan dan Diskusi}

Berdasarkan hasil FGD diketahui bahwa dukungan suami yang dirasakan istri meliputi adanya rasa empati, perhatian. Hal tersebut merupakan wujud adanya dukungan emosional. Seorang istri juga merasakan bahwa suami adalah penolong sejatinya, bahwa ketika ada masalah, suami selalu mampu menjadi penolongnya. Kondisi ini menunjukkan adanya dukungan instrumental.

Bentuk dukungan suami yang dirasakan istri tersebut sesuai dengan hasil penelitian Handayani (2017) serta berdasarkan review literatur (Adam, et al., 1996; Aycan \& Eskin, 2005; Erdwins, et al, 2001; King, et al, 1995; Wayne \& Stevens, 2006) pada dasarnya ada dua bentuk dukungan suami, yaitu dukungan emosi dan dukungan instrumental. Dukungan emosi fokus pada sikap pasangan seperti memberikan dorongan, memahami, adanya perhatian, penghargaan yang positif dan membimbing dengan penyelesaian masalah. Dalam hal ini termasuk kerelaan untuk mendengarkan, 
memberikan nasihat, dan menunjukkan perhatian dan fokus terhadap kesejahteraan pasangan.

Sebaliknya dukungan instrumental berhubungan dengan pertolongan nyata dari suami yang berhubungan dengan tugas-tugas rumah tangga dan pengasuhan anak (Adam, et al., 1996; Aycan \& Eskin, 2005; Erdwins, et al, 2001; King, 1995; Wayne \& Stevens, 2006). Dukungan instrumental dari suami meringankan beban tuntutan keluarga dan memungkinkan individu untuk mencurahkan lebih banyak waktu untuk bekerja, sedangkan dukungan emosional dari suami meningkatkan perasaan "self efficacy" tentang pekerjaan dan keluarga (Aycan \& Eskin, 2005). Menurut Gordon et al (2004) dukungan suami termasuk berbagi tanggung jawab tentang rumah dan pengasuhan, mendorong kemajuan karir, dan memberikan dukungan interpersonal.

Berkaitan dengan pengujian validitas modul, sejalan dengan pendapat Azwar (2012) bahwa jika suatu alat ukur mampu menghasilkan data akurat sesuai dengan tujuan ukurnya berarti alat ukur tersebut valid. Validasi dari para expert judgement baik bidang psikologi keluarga, psikologi I ndustri, litbang Himpaudi, maupun ahli media menunjukkan bahwa modul layak digunakan dengan revisi. Secara materi modul telah menjabarkan tentang adanya dukungan suami.

Secara khusus hasil analisis kualitatif expert judgement bidang psikologi keluarga mengkritisi bahwa dukungan yang diberikan suami ke istri sangat unik, maka perlu dipertimbangkan tentang pemenuhan kebutuhan seksual (dukungan emosi) dan dukungan finansial (dukungan instrumental). Hal ini memang tidak tersurat secara nyata dalam konten materi, karena dukungan suami dalam hal ini lebih mengarah pada penyelesaikan masalah peran ganda ibu bekerja.

Mayoritas riset menunjukkan bahwa dukungan suami dihubungkan dengan peningkatan fungsi pengasuhan bersama antara ayah dan ibu dan hubungan pengasuhan antara orang tua dan anak (Belsky, 1990; Erdwins, Buffardi, Casper, \& O'Brien, 2001; Ehrenberg, Gearing-Small, Hunter, \& Small, 2001). Dengan demikian, dukungan suami adalah persepsi istri tentang bantuan yang diberikan oleh suami berkaitan dengan upayaupaya mempertemukan tanggung jawab antara pekerjaan dan keluarga.

Sedangkan dari expert judgement bidang media beberapa hal perlu dicermati, diantaranya tentang penggunaan warna. Hal ini sesuai dengan pendapat Ardini \& Sarihati (2017) bahwa bahwa adanya warna dapat berpengaruh pada suasana dan kondisi psikologis seseorang. Hal ini karena warna merupakan salah satu aspek visual yang dapat 
ditangkap dan direspon secara cepat oleh indra penglihatan. Dengan demikian, warna juga perlu menjadi perhatian dalam pembuatan modul.

Berdasarkan hasil uji coba terbatas dan uji coba kelompok lebih luas menunjukkan adanya perubahan pengetahuan dan pemahaman tentang dukungan suami yang dirasakan para istri. Ketika para ibu bekerja mampu merasakan apa yang dilakukan suami sebagai suatu bentuk dukungan, maka akan tercapai keseimbangan kerja-keluarga. Studi Jacobs \& Gerson (2010) menunjukkan bahwa pasangan berkontribusi dalam menyeimbangkan peran pengasuhan dan karir. Kondisi demikian merupakan pertolongan yang sangat berarti berhubungan dengan konflik tanggung jawab antara pekerjaan dan keluarga (Erdwins, et al, 2001).

\section{Simpulan}

Hasil penelitian ini menghasilkan luaran produk modul dukungan suami melalui beberapa tahapan. Proses penelitian diawali dengan FGD dan wawancara untuk menggali data dalam untuk menyamakan persepsi tentang materi modul. Tahap selanjutnya menyusun prototype modul, melakukan uji validasi modul serta melakukan uji coba modul kelompok kecil.

Hasil penelitian menunjukkan bahwa 1). Materi modul dukungan suami meliputi dukungan emosional dan dukungan instrumental. 2). Hasil validasi modul menunjukkan bahwa secara tampilan maupun konsep termasuk dalam kategori baik, dengan sedikit revisi. Meskipun demikian, modul ini sesuai dalam mendukung pelatihan dukungan suami dalam mencapai keseimbangan kerja-keluarga. 3). Implementasi modul pada kelompok kecil menunjukkan bahwa pemahaman serta persepsi dukungan suami yang dirasakan peserta mengalami peningkatan. Hal ini menunjukkan bahwa modul dukungan suami yang telah disusun secara efektif mampu meningkatkan pemahaman dan keterampilan peserta dalam mencapai keseimbangan kerja-keluarga.

\section{Kepustakaan}

Adam, G. A., King, L.A., \& King, D.W. (1996). Relationship of job and family involvement, family social support, and work family conflict with job and life satisfaction. Journal of Applied Psychology, 81(4), 411-420. https://scihub.do/https://psycnet.apa.org/doiLanding?doi=10.1037\%2F00219010.81.4.411 
Ardini, E.N \& Sarihati, T. (2017). Pengaruh warna pada elemen interior ruang tunggu Rumah Sakit Ibu dan Anak terhadap psikologis pengunjung (Studi kasus Rumah Sakit Ibu dan Anak Melinda Bandung. Jurnal Idealog (Jurnal Ide dan Dialog $\begin{array}{llll}\text { Indonesia, } & 2 & \text { 330-342 }\end{array}$ https://journals.telkomuniversity.ac.id/idealog/article/view/1235/793

Aycan, Z. \& Eskin, M. (2005). Relative contribution of childcare, spousal support, and organizational support in reducing work family conflict for men and women : The case of Turkey. Sex Roles, 53(7/8), 453-471. DOI: 10.1007/s11199-005-7134-8 https://sci-hub.do/https://link.springer.com/article/10.1007/s11199-005-71348

Azwar, S. (2012). Penyusunan skala psikologi. Yogyakarta : Pustaka Pelajar.

Baran, H., (2012). The role of ethnic culture in work family balance among Armenian women in leadership positions in higher education. (Disertasi tidak dipublikasikan). University of Southern, California. https://search.proquest.com/openview/6f45c1c33345905f65fe865192fe3c24/1?pqorigsite $=$ gscholar $\&$ cbl $=18750 \&$ diss $=y$

Belsky, J. (1990). Parental and non parental child care and children's socioemotional development : A decade in review. Journal of Marriage and the Family, 52, 885-903. https://sci-hub.do/https://www.jstor.org/stable/353308?seq=1

Carlson, D. S., Kacmar, K. M., Wayne, J. H., \& Grzywacz, J. G. (2006). Measuring the positive side of the work-family interface: Development and validation of a work-family enrichment scale. Journal of Vocational Behavior, 68, 131-164. https://scihub.do/https://www.sciencedirect.com/science/article/abs/pii/S000187910500 $\underline{0448}$

Clark, S.C. (2000). Work/family border theory : A new theory of work/family balance. Human Relations, 53 (6), 747-769. https://scihub.do/https://journals.sagepub.com/doi/abs/10.1177/0018726700536001

Dewi, I.G.A.M. (2013). Anteseden dan konsekwensi konflik pekerjaan-keluarga-budaya. (Disertasi. Tidak dipublikasikan) Fakultas Ekonomi dan Bisnis. Universitas Gadjah Mada, Yogyakarta.

Ehrenberg, M.F., Gearing-Small, M., Hunter, M.A., \& Small, B.J. (2001). Childcare task division and shared parenting attitudes in dual-earner families with young children. Family Relations, 50(2), 143-153 https://scihub.do/https://onlinelibrary.wiley.com/doi/abs/10.1111/j.1741$\underline{3729.2001 .00143 . x}$

Erdwins, C.J., Buffardi, L.C., Casper, W.J., \& O'Brien, A.S. (2001). The relationship of women's role strain to social support, role satisfaction, and self-efficacy. Family $\begin{array}{llll}\text { Relations, } & 50 & \text { (3), } & \text { 230-238. }\end{array}$ hub.do/https://onlinelibrary.wiley.com/doi/abs/10.1111/j.1741$\underline{3729.2001 .00230 . x}$ 
Fischlmayr, I.C., \& Kollinger, I. (2010). Worl life balance - a neglected issue among Auatralian female expatriates. The International Jounal of Human Resources Management, 21(4), 455-487 https://scihub.do/https://www.tandfonline.com/doi/abs/10.1080/09585191003611978

Ford, M.T, Heinen, B.A. \& Langkamer,K.L. (2007) Work and family satisfaction an conflict : A metanalisis of cross-domain relations. Journal of Applied Psychology, 92(1), 5780. https://sci-hub.do/https://psycnet.apa.org/doiLanding?doi=10.1037/0021$\underline{9010.92 .1 .57}$

Gall, M.D., Gall, J.P. \& Borg, W.R. (2003). Educational research: An Introduction (7th ed). London : Longman, Inc

Gordon, JR; Whelan-Berry, \& Karen, S. (2004). It takes two to tango: an empirical study of perceived spousal/ partner support for working women. Women in Management Review, 19(5), 260-273 https://scihub.do/https://www.emerald.com/insight/content/doi/10.1108/096494204105 $\underline{45980 / \text { full/html }}$

Greenhaus, J. H., Collins, K. M., \& Shaw, J. D. (2003). The relation between work family balance and quality of life. Journal of Vocational Behavior, 63, 510-531. https://scihub.do/https://journals.aom.org/doi/abs/10.5465/amr.2006.19379625

Greenhaus, J. H., Ziegert, J.C., \& Allen, T.D. (2011). When family-supportive supervision matters : Relations between multiple sources of support and work family balance. Journal of Vocational Behavior. 80, 266-275 https://scihub.do/https://www.sciencedirect.com/science/article/abs/pii/S000187910200042 $\underline{8}$

Grzywacz, J. G. \& Carlson, D. S. (2007). Conceptualizing work-family balance: Implications for practice and research. Advances in Developing Human Resources, 9(4), 455-471. https://scihub.do/https://journals.sagepub.com/doi/abs/10.1177/1523422307305487

Grzywacz, J. G., \& Marks, N. F. (2000). Reconceptualizing the work-family interface: An ecological perspective on the correlates of positive and negative spillover between work and family. Journal of Occupational Health Psychology, 5, 111-126.

Halpern,D.F. (2005) Psychology at the intersection of work and family : Recommendations for employer, working families, and policymakers. American psychologist, 60, 397409

hub.do/https://psycnet.apa.org/doiLanding?doi=10.1037\%2F0003-

https://sci$\underline{066 X .60 .5 .397}$

Handayani, A. (2008). Pengaruh dukungan suami terhadap konflik peran ganda pada dosen-dosen wanita. Psiko Wacana. 7 (1), 1-9

Handayani, A., Maulia, D., Yulianti, P.D. (2012). Kinerja dosen berdasarkan konflik keja keluarga dan motivasi berprestasi. Dalam Suwarno Widodo, Nur Hidayat, Suyoto, Arisul U. (Eds.), Prosiding Seminar Hasil-hasil Penelitian (hal 111-116). Semarang : Lembaga Penelitian dan Pengabdian Kepada Masyarakat. IKIP PGRI Semarang. 
Handayani, A. Afiatin, T., Adiyanti, M.G. (2015). Studi eksplorasi makna keseimbangan kerja keluarga pada ibu bekerja. Dalam Latipun, Diah karmiati, Rachmah Nur A (Eds.), Prosiding Seminar Nasional Psikologi dan Kemanusian, Perkembangan Manusia dan Kesejahteraan psikologis". (hal 30-36). Malang : UMM Press http://mpsi.umm.ac.id/files/file/30-36\%20Arri\%20Handayani.pdf

Handayani, A \& Munawar, M. (2015). Keterlibatan peran ayah dalam mengoptimalkan tumbuh kembang anak (tinjauan teori identitas). Dalam Delila Saskia, Ghitha Loka, Feri Muhammad, Irwan Gunawan (Eds.), Prosiding Seminar nasional Peran Pendidikan Anak Usia Dini (PAUD) dalam meningkatkan mutu pendidikan di Indonesia. (hal 623-628). Bandung : Rizqi Offset.

Handayani, A., 2017. Model keseimbangan kerja-keluarga pada ibu bekerja. Disertasi.Tidak diterbitkan. Yogyakarta: Fakultas Psikologi Universitas Gadjah Mada.

Jacobs, J. A., \& Gerson, K. (2010). Overworked individuals or overworked families?: Explaining trends in work, leisure, and family time. Work and Occupations, 28, 4063.

https://scihub.do/https://journals.sagepub.com/doi/abs/10.1177/0730888401028001004

Jianwei, Z., \& Yuxin, L.(2011). Antecedent of work family conflict : Review and prospect. International Journal of Business management, 6(1), 89-101 http://citeseerx.ist.psu.edu/viewdoc/download?doi=10.1.1.686.5428\&rep=rep1\& type $=$ pdf

Judge, T.A., \& Colquitt, J.A. (2004). Organizational justice and stress : The mediating role of work family conflict. Journal of Applied Psychology, 89 (3), 395-404. https://scihub.do/https://psycnet.apa.org/doiLanding?doi=10.1037\%2F0021$\underline{\text { 9010.89.3.395 }}$

King, L. A., Mattimore, L. K., King, D. W., \& Adams, G. A. (1995). Family support inventory for workers: A new measure of perceived social support from family members. Journal of Organizational Behavior, 16, 235-258. https://scihub.do/https://onlinelibrary.wiley.com/doi/abs/10.1002/job.4030160306

Kinnunen, U.,\& Mauno, S. (1998) Antecedents and outcomes of work-family conflict among employed women and men in Finland. Human Relations, 51(2), 157-162 https://scihub.do/https://journals.sagepub.com/doi/abs/10.1177/001872679805100203

Lee, N.Y., Zvonkovic, A.M., \& Crawford, D.W. (2013). The impact of work-family conflict and facilitation on women's perceptions of role balance. Journal of Family Issues. 20(10), 1-23. hub.do/https://journals.sagepub.com/doi/abs/10.1177/0192513X13481332

Major, V.S., Klein, K.J., \& Ehrhart, M.G.. (2002). Worktime, work interference with family and psychological distress. Journal of Applied Psychology, 87(3),.427-436 https://sci-hub.do/https://psycnet.apa.org/doiLanding?doi=10.1037/00219010.87.3.427 
Marks, S.R., \& MacDermid,S.M.(1996). Multiple roles and the self : A theory of role balance. Journal of Marriage \& the family, 58, 417-432 https://scihub.do/https://www.jstor.org/stable/353506?seq=1

Martins LL, Eddleston KA \& Veiga JF. (2002) Moderators of the relationship between work-family conflict and career satisfaction. Academy of Management Journal, 45, 399-409.

https://scihub.do/https://journals.aom.org/doi/abs/10.5465/3069354

Parasuraman, S., \& Simmers, C. A. (2001). Type of employment, work-family conflict and well-being: A comparative study. Journal of Organizational Behavior, 22, 551-569. https://sci-hub.do/https://onlinelibrary.wiley.com/doi/abs/10.1002/job.102

Putri, P.S., Respati, W.S., \& Safitri, (2009). Makna hidup pada perempuan dewasa yang berperan ganda. Jurnal Psikologi, 7(2), 43-51. https://digilib.esaunggul.ac.id/public/UEU-Journal-5000-WinantiSiwi.pdf

Ruderman, M.N., Ohlott, J.P., Panser, K. \& King, S.N. (2002). Benefits of multuple roles for managerial women. The Academy of Management Journal. 45(2), 369-386 https://sci-hub.do/https://journals.aom.org/doi/abs/10.5465/3069352

Valcour, M. (2007). Work-based resources as moderators of the relationship between hours and satisfaction with work-family balance. Journal of Applied Psychology, 6, 1512-1523.

hub.do/https://psycnet.apa.org/doiLanding?doi=10.1037\%2F0021-

https://sci$\underline{9010.92 .6 .1512}$

Voydanoff, P (2004). The effects of work demands and resources on work to family conflict and facilitation. Journal of Marriage and the Family, 66, 398-412 https://scihub.do/https://onlinelibrary.wiley.com/doi/abs/10.1111/i.1741$\underline{3737.2004 .00028 . x}$

Wadsworth, L.L \& Owens, B.P. (2007). The effect of social support on work family enhacement and work family conflict in the public sector. Public Administration Review, 32, 75-87 https://scihub.do/https://onlinelibrary.wiley.com/doi/abs/10.1111/j.15406210.2006.00698.x

Wayne, R. \& Stevens. (2006). The role of identity and work-family support in workfamily enrichment andits work related consequences. Journal of Vocational Behavior, 69, 445-461.

https://scihub.do/https://www.sciencedirect.com/science/article/abs/pii/S0001879 $10600 \quad 0807$ 